\title{
Research article: Profile of women members of village Grampanchayat and their constraints
}

J. H. Gaikwad

Article Chronicle:

Received :

15.02.2020;

Revised:

05.10.2020;

Accepted :

24.10.2020

KEY WoRds :

Profile, Women

members,

Grampanchayat,

Constraints

Author for correspondence :

J. H. Gaikwad

Agriculture Technology

School, Puntamba,

Ahmednagar (M.S.) India

Email: jh_gaikwad@

rediffmail.com
SUMMARY : The women members of Grampanchayat might be facing certain problems while performing their role. Out of 250 women Grampanchayat members in all 125 were covered under the study by following the $\mathrm{N}^{\text {th }}$. A majority of the women members of Grampanchayat under study were from middle age group. Most of them were having medium size of family, having experience upto 5 years, medium level of sources of information, medium level of cosmopoliteness, medium social participation, medium level of annual income, medium size of land holding, medium leadership behaviour, medium level of motivation, medium level of attitude and also medium level of knowledge. The important problems reported by a considerable number of the respondents had lack of knowledge about duties and responsibilities of Grampanchayat, provision of inadequate grants by the Government, lack of training from concerned agency about the functions of Grampanchayat, lack of time left after domestic and farm work to the respondents.

How to cite this article : Gaikwad, J.H. (2020). Profile of women members of village Grampanchayat and their constraints. Agric. Update, 15(4): 407-410; DOI : 10.15740/HAS/AU/15.4/407-410. Copyright@ 2020: Hind Agri-Horticultural Society. 